\title{
Various Technologies for Producing Energy from Wave: A Review
}

\author{
Sajjad Mehrangiz ${ }^{\mathrm{a}}$, Yunus Emami ${ }^{\mathrm{a}}$, Sayed H. Sayed Sadigh ${ }^{\mathrm{a}}$, Ahmad Etemadi ${ }^{\mathrm{b}}$ * \\ ${ }^{a}$ Urmia University of Technology, Mechanical Engineering Department, Urmia, Iran \\ ${ }^{b}$ Urmia University of Technology, Chemical Engineering Department, Urmia, Iran
}

\begin{abstract}
With considering the increasing of global temperature, and also the concern of global climate change, many policy makers worldwide have been accepted the importance of reducing greenhouse gas emissions, in particular from the power industries so the importance of the renewable energy is obvious. Wave energy is one of the renewable energy sources. And has the potential to play a valuable part in a sustainable energy future. Wave energy is also one of the predictable energy sources that depending on oscillating the surface of water. The wave energy system for generation electricity in the last few years has been growing rapidly. There are several methods that have been proposed to classify wave energy converters with considering working principle, location and size such as the oscillating water column (OWC), oscillating body systems, overtopping converters and etc. In almost every system, optimal wave energy absorption includes some kind of resonance, which implies that the geometry and size of the structure are linked to wavelength. The resonance allows to relatively small device to producing large power. This paper discusses about the various technology of wave energy converters.
\end{abstract}

Keywords: Renewable energy, wave energy, various technology, oscillating body systems, oscillating water column (OWC), Heaving buoys.

\section{Introduction}

By increasing the power demands in the world and global concerns about the greenhouse gases that released from burning the fossil fuels, the requirement to clean sources of energy and their conversion technologies is obvious. The most plentiful renewable energy source in our planet by far is solar radiation: 170,000 TW fall on Earth. Harvesting this energy is difficult because of its dilute and erratic nature. Oceans cover $71 \%$ of Earth's surface. In the tropics, they absorb sunlight, and the top layers heat up to some $25^{\circ} \mathrm{C}$. Warm surface waters from the equatorial belt flow pole ward, melting both the arctic and the Antarctic ice. The resulting cold waters return to the equator at great depth, completing a huge planetary thermosyphon. There are many techniques for deriving electricity from the ocean such as tidal power, wave power, ocean thermal energy conversion, ocean currents, ocean winds and salinity gradients. Of these, the three most well-developed technologies are tidal power, wave power and ocean thermal energy conversion. The kinetic energy present in marine and tidal currents can be converted to electricity using relatively conventional turbine technology. Harnessing the kinetic energy in waves presents a different set of technical challenges and a wide variety of designs have been suggested. Ocean thermal energy conversion is possible in locations with large variety temperatures, getting energy using a heat engine. Salinity gradients can be exploited for energy extraction through the reverse electrodialysis[1,2,3] and osmotic process[4.5]. In comparison to another sources of renewable energy the ocean power technologies are poised on the threshold of commercial development. The stronger winds blowing over

\footnotetext{
* Manuscript received July 10, 2012; revised August 10, 2012.

Corresponding author. Tel.: +9844135541180-1; fax: +984413554184; E-mail address: ahmadetemadi112@gmail.com.
} 
the water's surface are cased to creating the more powerful waves. These primarily occurs in the areas between $30^{\circ}$ and $60^{\circ}$ latitude, both north and south (Fig. 1 (a)). According to the U.S. Department of Energy, traditional (barrage) tidal power requires a difference between high tide and low tide of at least 16 feet. There are only about 40 such sites worldwide (Fig. 1 (b)) Tidal stream, on the other hand, simply needs a strong current and, in the case of a tidal fence, a narrow inlet to span.

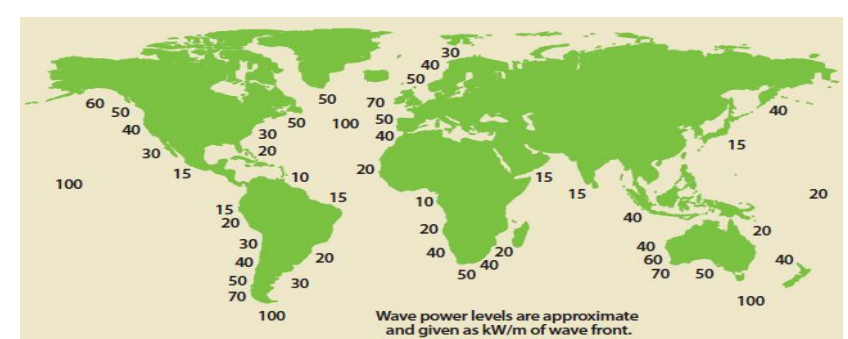

(a)

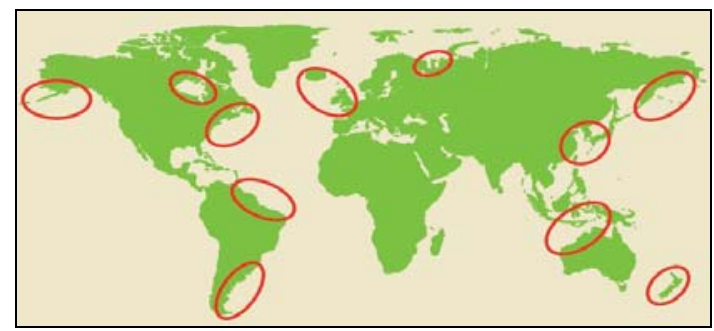

(b)

Fig. 1. (a) Estimate global distribution of wave power levels; (b) Areas appropriate for traditional tidal power [6]

\section{Various Technology}

According to location, working principle and size, There are several methods to receiving energy from wave energy such as: oscillating water column, oscillating bodies, overtopping. This classification based mostly on working principle.

\subsection{Fixed-structure OWC}

Based on various energy-extracting methods, Fixed-structure OWC has been developed and build in open coastal waters. It mostly is located on the shoreline. These devices generally are standed on the sea bottom or are fixed to a rocky cliff [7]. There are several advantages in the shoreline devices such as easier installation and maintenance, and do not require deep-water moorings and long underwater electrical cables. The oscillating water column (OWC) device includes a partly submerged concrete or steel structure, open below the water surface, inside which air is trapped above the water free surface (Fig. 2). The oscillating motion of the internal free surface that is produced by the waves makes the air to flow through a turbine that drives an electrical generator. Their installed power capacity is (or was) in the range $60-500 \mathrm{~kW}$ [7]. The most critical issues in OWC technology are the design and construction of the structure (apart from the air turbine), it is most influential on the economics of energy produced from the waves.

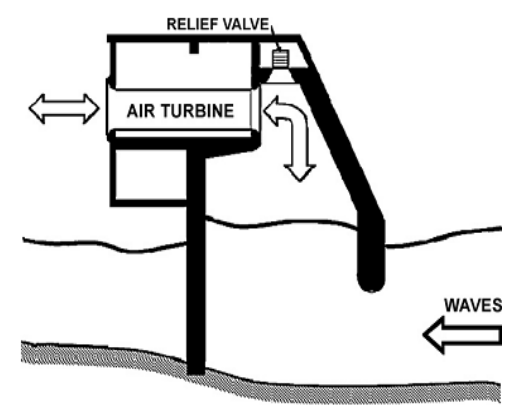

Fig. 2. Cross sectional view of a bottom-standing OWC (Pico plant) [7]

\subsection{Floating-structure OWC}

One of the geometry for a floating OWC is the backward bent duct buoy (BBDB). In this geometry (BBDB), the OWC duct is bent backward from the incident wave direction (Fig. 3) (which was found to 
be advantageous in comparison with the frontward facing duct version) [8]. In this way, the length of the water column could be made sufficiently large for resonance to be achieved, while keeping the draught of the floating structure with inacceptable limits. The BBDB converter was studied (including model testing) in several countries (Japan, China, Denmark, Korea, Ireland) and was used to power about one thusand navigation buoys in Japan and China [9,10]. It is a multi-resonance converter with several vertical OWCs of different lengths, each chamber being connected to an air turbine [11].

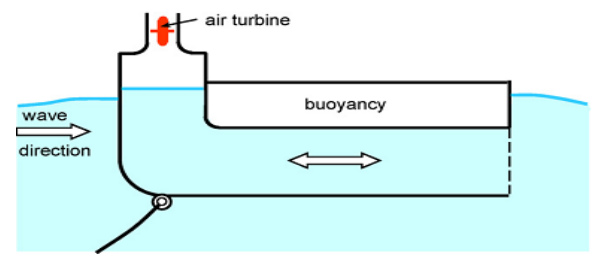

Fig. 3. Schematic representation of the Backward Bent Duct Buoy (BBDB) [7]

\section{Oscillating Body System}

Offshore devices are basically oscillating bodies, either floating or fully submerged. In comparison to first generation system the offshore wave energy converters are more complex. There are additional problem such as mooring, access for maintenance and the need of long underwater electrical cables that cased to hindered their development.

\subsection{Single-body heaving buoys}

The simplest oscillating-body device is the heaving buoy reacting against a fixed frame of reference. The buoy was equipped with an air turbine and could be phase-controlled by latching. A version of the taut-moored buoy concept is being developed at Uppsala University, Sweden, and uses a linear electrical generator (rather than a piston pump) placed on the ocean floor [12]. By following the Fig. 4, springs attached to the translator of the generator store energy during half a wave cycle and simultaneously act as a restoring force in the wave troughs. Sea tests off the western coast of Sweden of a $3 \mathrm{~m}$ diameter cylindrical buoy are reported in [12].

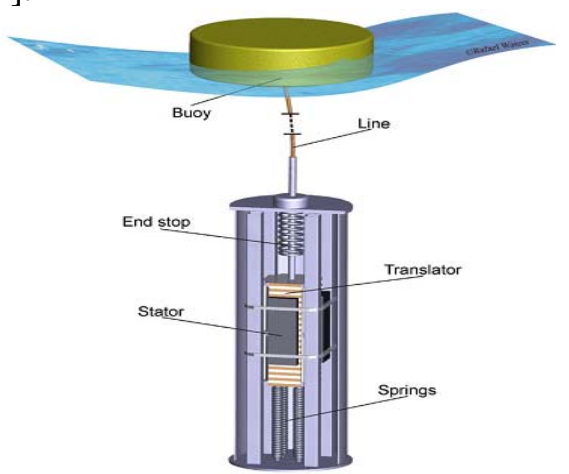

Fig. 4. Swedish heaving buoy with linear electrical generator (courtesy of Uppsala University)[7]

\subsection{Two-body heaving systems}

In the two-body heaving system energy is converted from the relative motion between two bodies oscillating differently. The hydrodynamics of two-body systems was theoretically analysed in detail by Falnes [13]. The Schematic representation of the IPS buoy is shown in Fig. 5, is one of the most interesting absorbers for wave energy conversion that consists of a buoy rigidly connected to a fully submerged vertical tube (the so-called acceleration tube) open at both ends. The tube contains a piston whose motion relative to the floater-tube system drives a power take-off (PTO) mechanism. 


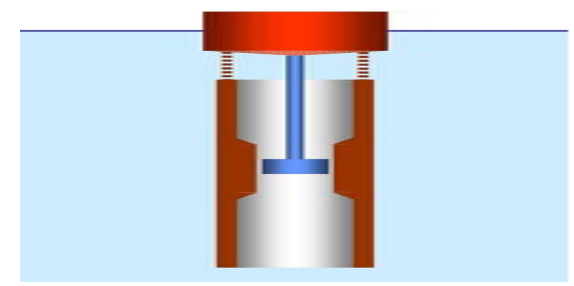

Fig. 5. Schematic representation of the IPS buoy [7]

\subsection{Fully submerged heaving system}

The Archimedes Wave Swing (AWS) was the first converter using a linear electrical generator. It is fully submerged heaving device that was basically developed in Holland and consist of an oscillating upper apart (the floater) and a bottom-fixed lower part (the basement) Fig. 6 (a) [14]. The wave crest and wave trough cased to floater be pushed down and moves up and this motion is resisted by a linear electrical generator with the interior air pressure acting as a spring.

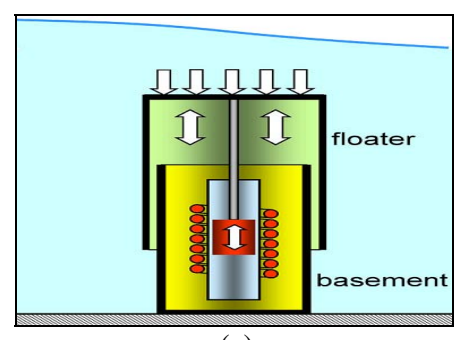

(a)

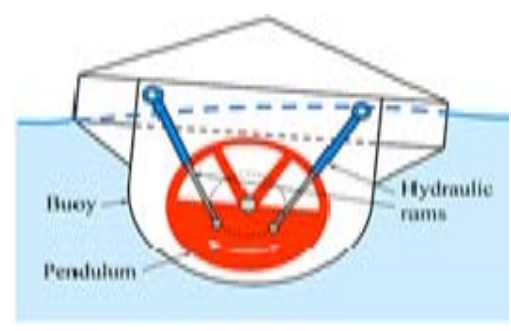

(b)

Fig. 6. (a) Schematic representation of the Archimedes Wave Swing [14]; (b) Schematic representation of the Searev [17]

\subsection{Pitching devices}

In the above systems the energy conversion is associated with a relative translational motion but in the pitching device systems it is based on relative rotation (mostly pitch) rather than translation. This is the remarkable case of the nodding Duck (created by Stephen Salter, from the University of Edinburgh), that has been appearing since the1970s and early1980s [15], that are probably the best known offshore devices among those, and which of several versions were developed in the following years [16]. One of the example of this oscillating-body systems is Searev Wave energy converter developed at Ecole Centrale de Nantes, France [17], it is a floating devices that consist of a heavy horizontal-axis wheel serving as an internal gravity reference (Fig. 6 (b)).

\subsection{Bottom-hinged system}

These devices are based on the inverted pendulum hinged at the sea bed concept. The mace is invented by Stephen Salter [20]. As shown in Fig. 7, the bottom-hinged system consists of a buoyant spar, with symmetry about a universal joint at the sea vertical axis that can swing about a universal joint at the sea bottom. The power take-off reaction to the sea bed is via a set of cables. The cables wound several times round a winch-drum leading both fore and aft in the prevailing wave direction. The wave-activated reciprocating rotation of the drum is converted into useful energy by means of a hydraulic system.

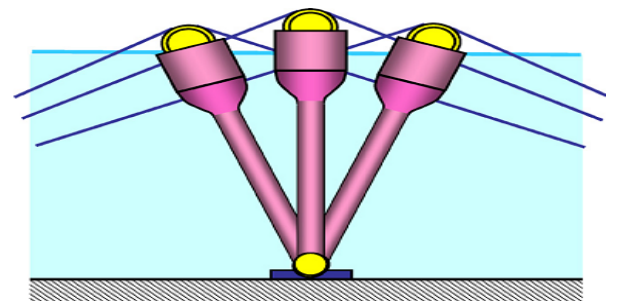

Fig. 7. The swinging mace in three angular positions [7] 


\subsection{Many-body systems}

In some cases, the device consists of a large set of floating point absorbers reacting against a common frame and sharing a common PTO. The waves make the buoys to swing about their common on reference frame and pump oil into the hydraulic circuit. One of the example of Many-body systems is A1/10-scale $24 \mathrm{~m}$ long $5.5 \mathrm{~kW}$ model with 10 buoys on each side was deployed in 2006 in Nissum Bredning, Denmark, and tested with grid connection for a couple of years [18].

\section{Over Topping Converters}

The capturing the water that is close to top of wave and introduce it, by over spilling into a reservoir where it is stored at a level higher than the average free-surface level of the surrounding sea is a different way of converting the wave energy. Unlike the cases of oscillating body and OWC wave energy convertors, the hydrodynamics of overtopping devices are strongly non-linear. One example of the over topping converters is the Wave Drang floating that consists of two wave reflectors focusing the incoming waves towards a doubly curved ramp, a reservoir and a set of low-head hydraulic turbines (Fig. 8) [19].

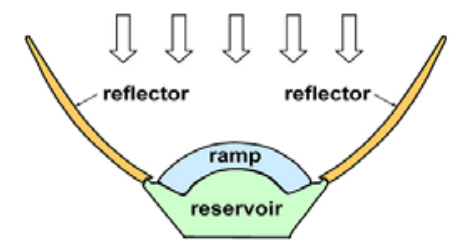

Fig. 8. Plan view of Wave Dragon [19]

\section{Conclusion}

The wave energy systems for generation electricity in the last few years had been growing rapidly and also energy utilization in other parts of the world has been developing quickly. The testing under real sea condition is final stage of modeling wave energy converts. In almost every system, optimal wave energy absorption includes some kind of resonance, which implies that the geometry and size of the structure are linked to wavelength. For these reasons, if pilot plants are to be tested in the open ocean, they must be large structures. There is some snag that has hindered the development of wave energy systems such as: the high costs of constructing, deploying, maintaining and testing large prototypes under sometimes very harsh environmental conditions. In most cases the only solution of these problems was possible only with substantial financial support from governments.

\section{References}

[1] Pattle RE. Production of electric power by mixing fresh and salt water in the hydroelectric pile. Nature, 1954; 174:660.

[2] Pattle RE. Electricity from fresh and salt water-without fuel. Chem. Proc. Eng., 1955; 35:351-354.

[3] Pattle RE. Improvements to electric batteries. Patent GB 731729, 1955.

[4] Loeb S. Osmotic power plants. Science, 1975;189:654-655.

[5] Loeb S. Production of energy from concentrated brines by pressure retarded osmosis. 1. Preliminary technical and economic correlations. Membr J. Sci., 1976; 1:49-63.

[6] Thorpe TW. An overview of wave energy technologies: Status, Performance and Costs. Presented at: International One Day Seminar: Wave Power, Moving Towards Commercial Viability, 1999.

[7] António F. Falcão de O. Wave energy utilization: A review of the technologies. Renewable and Sustainable Energy Reviews, 2010; 14:899-918.

[8] Masuda Y, Mc Cormick ME. Experiences in pneumatic wave energy conversion in Japan. Mc Cormick ME, Kim YC, editors. Utilization of Ocean Waves-Wave To Energy Conversion. New York: ASCE; 1987:1-33.

[9] Masuda Y, et al. High performance of cylinder float backward bent duct buoy (BBDB) and its use in European seas. In: Proceedings of (First) European Wave Energy Symposium,1993:323-337.

[10] Masuda Y, Kimura H, Liang X, Gao X, Mogensen RM, Andersen T. Regarding BBDB wave power generation plant. In: 
Proceedings of 2nd European Wave Power Conference, 1995:69-76.

[11] Lye JL, Brown DT, Johnson F. An investigation into then on-linear effects resulting from air cushions in the recon oscillating water column (OWC) device. Presented at: Proceedings of 28th International Conference on Ocean Offshore Arctic Engineering Hawaii, 2009.

[12] Waters R, Stalberg M, Danielsson O, Svensson O, Gustafsson S, Stromstedt E, et al. Experimental results from sea trials of an offshore wave energy system. Appl. Phys. Lett., 2007; 90(3) [ArtNo.034105].

[13] Falnes J. Wave-energy conversion through relative motion between two single-mode oscillating bodies. J Offshore Mech Arctic Eng, 1999; 121:32-38.

[14] Beatty SJ, Buckham BJ, Wild P. Frequency response tuning for a two-body heaving wave energy converter. In: Proceedings of 18th International Offshore Polar Engineering Conference, 2008:342-348.

[15] Salter SH. Wave power. Nature; 1974; 249:720-724.

[16] Salter S. Looking back. Cruz J., editor. Ocean Wave Energy. Berlin: Springer; 2008:7-39.

[17] Babarit A, Clement AH, Gilloteaux JC. Optimization and time-domain simulation of the SEAREV wave energy converter. In: Proceedings of 24th International Conference Offshore Mechanics Arctic Engineering, 2005:703-12.

[18] Wave star energy. [accessed20.10.2009] [Online]. Available: http://www.wavestarenergy.com/

[19] Kofoed JP, Frigaard P, Friis-Madsen E, Sørensen HC. Prototype testing of the wave energy converter wave dragon. Renewable Energy, 2006; 31:181-9.

[20] Salter SH. The swing ingmace. In: Proceedings of Workshop Wave Energy R\&D., 1992:197-206. 